\title{
Decision Support System: A Prototype for Determining Rice Price Based on Its Quality Measurement
}

\author{
Rizka Hadiwiyanti*, Prisa Marga Kusumantara, Dedi Anugrah, Tri Lathif MS \\ Department of Information System \\ Universitas Pembangunan Nasional "Veteran" Jawa Timur \\ Surabaya, Indonesia \\ *e-mail: rizkahadiwiyanti.si@upnjatim.ac.id
}

\begin{abstract}
Quality measurement of rice is an important and necessary activity before it is sold to market. By distinguishing its quality, pricing will also be suitable by the physical characteristics of rice delivered by farmers. This paper proposed a prototype of DSS application to assist intermediaries in determining the price of rice according to its quality. Fuzzy triangular numbers and AHP method is used to evaluate and assess the rank of rice quality. The evaluation criterion are whiteness, grain shape, foreign materials, moisture content and damaged grains. Pricing is based on the Indonesian domestic retail prices in 2017.
\end{abstract}

\section{Keywords-decision support system; rice quality, price}

\section{INTRODUCTION}

Rice is a strategic commodity that plays a vital role in the economy and national food security, as well as being the primary basis for future agricultural revitalization. In line with population growth, demand for rice in the period 2005-2025 is projected to increase [1]. Based on food security portal [2], rice production in Indonesia reached approximately 77 million tons in 2016. Fulfillment of rice demand must be complemented by an increase in its quality.

In general, farmers in Indonesia deliver their milled rice to the middlemen in their village with a different amount of weight. The middlemen mostly do not evaluate their quality and give the same price for all milled rice. This causes the farmers dissatisfied with the prices that given by middlemen. On the other hand, intermediaries do not have an adequate system to evaluate their quality. They can only check the quality manually and cannot determine the appropriate price for each sack of rice.

Based on these problems, a system that can assist intermediaries in evaluating the quality of rice is needed so that it can provide an appropriate price. A prototype of decision support system was developed to assess the quality of rice using the Fuzzy triangular numbers and AHP method and determine its prices. The criterion that will be evaluated includes whiteness, grain shape, foreign materials, moisture content and damaged grains. Pricing is based on the Indonesian domestic retail price [3].

\section{RELATED WORK}

For developing policies that encounter the objectives of decision makers, it needs information to have a better understanding of the possible outcomes of their decision. A decision support system could help them to process and analyze data and information required for making decisions [4][5]. For the agricultural domain, a system named AgroDSS was developed to bridges the gap between the system of agricultural and decision support methodology [6]. Another decision support systems application is proposed to help farmers predicting crop productivity under different particular climate [7]. Decision support system was also used to stimulate food security strategy in terms of food supply [8].

Other studies are developed fuzzy based decision support system for qualitative grading of milled rice [9]. Fuzzy decision support system was demonstrated to irrigation system [10][11]. Another study presented fuzzy logic tool was developed to classify wine quality [12]. Fuzzy set and Analytical Hierarchy Process (AHP) was applied to improved accuracy of the assessment process of land suitability [13].

\section{DESIGN OF Proposed Prototype}

The proposed decision support system prototype provides a means to evaluate rice quality and determine the appropriate price for each sack of rice. A DSS application desktop-based is developed as Graphical User Interface (GUI) in Visual Basic using Visual Studio tool and MySQL database for the ease of intermediaries and farmers.

Based on fig. 1, the user inputs the criteria and alternative data. In this experiment, five criterion and alternative values 
are entered by operator or intermediaries. Next, the system evaluates all values using the Fuzzy-AHP method then display the results. Details of the Fuzzy-AHP process is depicted in fig 2. In this experiment, five alternatives data were examined. The results of the Fuzzy-AHP process is the rank of the highest to lowest quality of rice. The price of rice is determined according to its quality rank. All results of evaluation and pricing are displayed on the GUI so that farmers can also see the results.

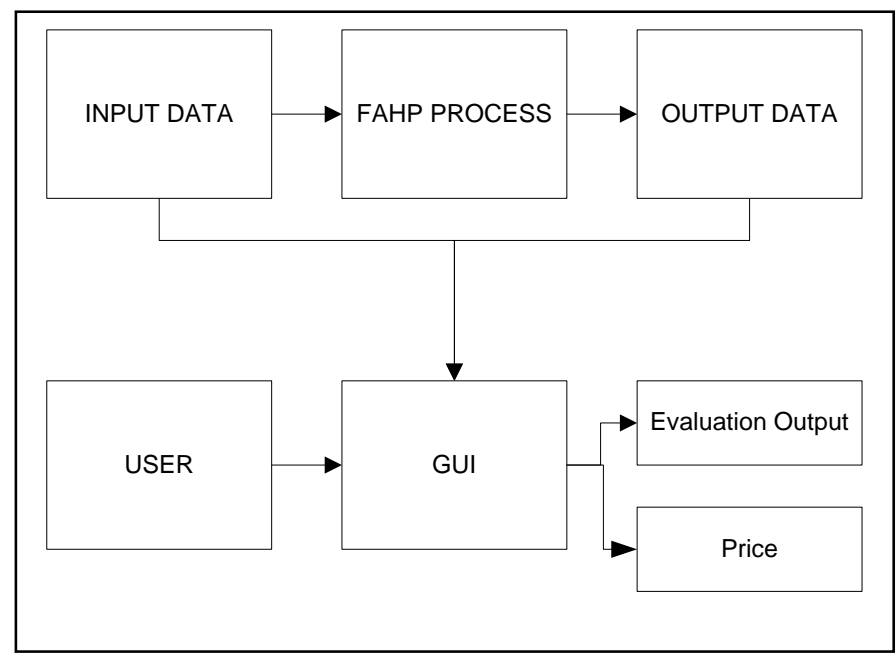

Fig. 1. The interaction between user and DSS application

There are five criteria that will be evaluated. The first is whiteness. Whiteness is a combination of varietal physical characteristics and the degree of milling. In milling, the whitening and polishing significantly affect the whiteness of the grain. Polishing after whitening is carried out to improve the appearance of the white rice [14]. Intermediaries prefer the color of whiter rice to attract buyers.

The second is grain shape. Long grain rice has a higher selling price than medium or short grain rice. Intermediaries is willing to offer higher value to them. The third criteria is foreign materials. Foreign materials are foreign objects that are not classified as rice, such as scrap wood, soil, sand, stalks of rice, other grains, etc. [15]. The less the percentage of foreign materials, then the higher the level of its preference, and vice versa.

The fourth criteria is moisture content. Moisture content is the weight of water contained in paddy or rice. It is usually referred to the wet basis meaning the total weight of the grain including the water [16]. The lower the percentage of moisture content, then the higher the level of its preference. The last criteria is damage grains. Damage grain is damaged head rice, broken rice and groats white/clear, white whitewash, yellow and red have more than one other color spots or freckles [16]. Damage grain in large capacity will get a low preference.

The rice quality in Indonesia is classified into two, premium rice and medium rice. The prices of premium and medium rice, regulated by the government, are different in each region. In 2017, the highest retail price for premium rice was IDR $13,600 / \mathrm{kg}$, whereas the highest retail price for medium rice was IDR $10,250 / \mathrm{kg}$. Both are the highest retail prices in the Papua region. In Java and Bali regions, the retail price of premium rice is IDR $12,800 / \mathrm{kg}$ and medium rice is IDR $9,450 / \mathrm{kg}$.

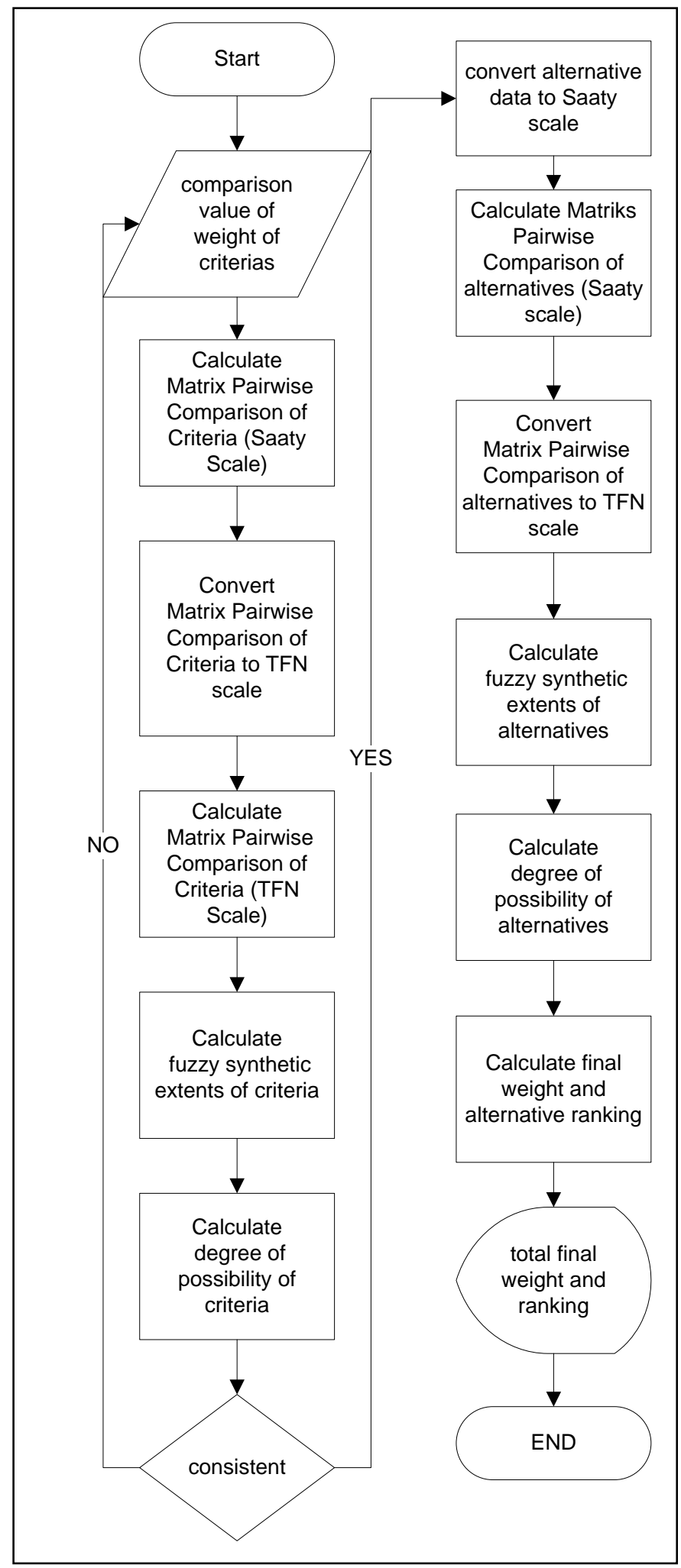

Fig. 2. Details of the Fuzzy-AHP process 
Determining the price of rice adjusts to the prevailing market prices in each region, referring to the highest retail price regulated by the government. For instance, in one of the villages on Java Island, the highest rate of rice is IDR 11,500 / $\mathrm{kg}$, and the lowest is IDR $8,000 / \mathrm{kg}$. Then, the middlemen and farmers agreed to determine the price interval between the highest and lowest price as in fig. 3 .

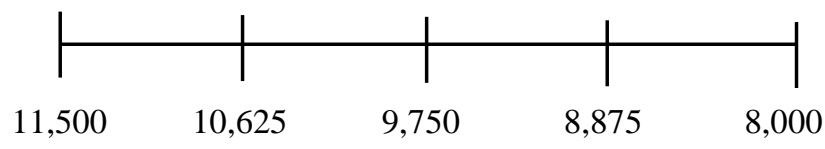

Fig. 3. Example of price interval of rice in a village on Java island

Quality rice that has been evaluated, is sorted from the highest to the lowest quality. Pricing for the highest to the lowest quality rice is adjusted to determine the retail price of rice. Thus, each farmer receives a different price according to their rice quality. Form design of calculation price of rice is shown in fig 4.

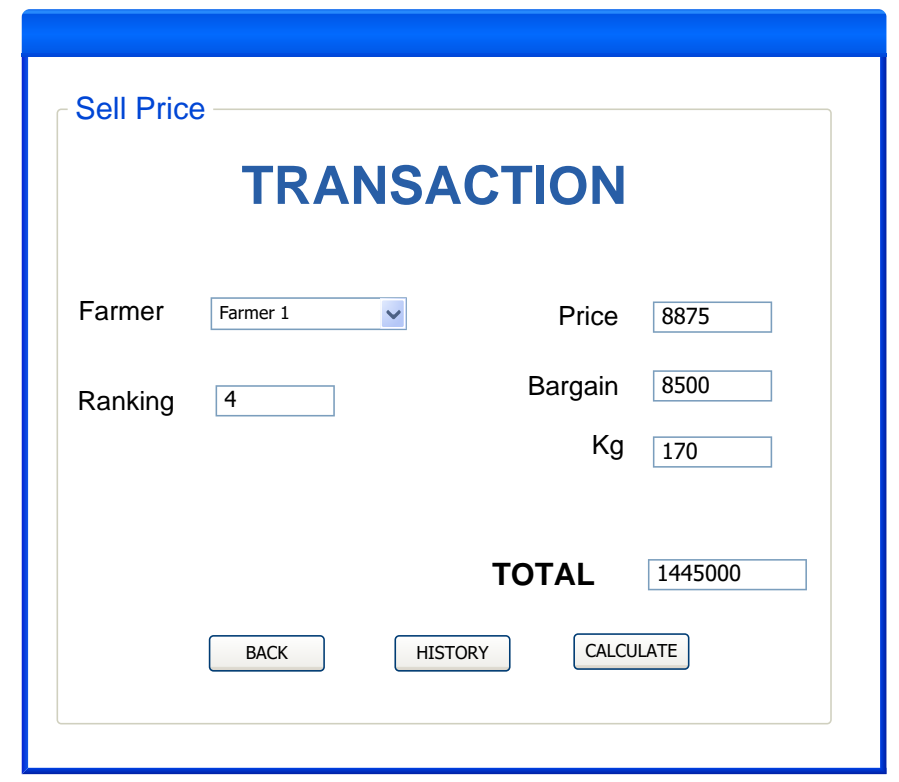

Fig. 4. Form design of calculation price of rice for each farmer

\section{CONCLUSION}

Middleman has limitations in determining price of rice. DSS application could assist middlemen to provide prices that are in accordance with the quality of rice delivered by farmers. In determining prices, the reference used is Indonesian domestic retail prices in 2017. For further research, other rice quality assessment criteria can be added to improve this prototype so that the assessment can cover all aspects.

\section{ACKNOWLEDGMENT}

The authors would like to thank the Dean of the Faculty of Computer Science, Universitas Pembangunan Nasional "Veteran" Jawa Timur for providing financial support for this research publication.

\section{REFERENCES}

[1] Indonesian Agency for Agricultural Research and Development, http://en.litbang.pertanian.go.id/, accessed on August, 2018

[2] The Food Security Portal, http://www.foodsecurityportal.org/indonesia, accessed on August, 2018

[3] Ministry of Trade of the Republic of Indonesia, http://jdih.kemendag.go.id/backendx/image/regulasi/25010739_Permend ag_No.57_Tahun_2017.pdf, accessed on August, 2018

[4] D.C. Rose, et al., "Decision support tools for agriculture: Towards effective design and delivery," in Agric. Syst., vol. 149, pp. 165-174, 2016.

[5] L.V. Dicks, J.C. Walsh, W.J. Sutherland, "Organising evidence for environmental management decisions: a ' $4 \mathrm{~S}$ ' hierarchy," in Trends in Ecol. \& Evol., vol 29, pp. 607-613, 2014.

[6] M. Kukar, et al., "AgroDSS: A decision support system for agriculture and farming," in Comput. and Electron. in Agric., 2018.

[7] N. Gandhi, L.J. Armstrong, and O. Petkar, "Proposed decision support system (DSS) for Indian rice crop yield prediction,” 2016 IEEE Technol. Innov. in ICT for Agric. and Rural Dev.t (TIAR), pp. 13-18, July 2016.

[8] A. Ferjani, S. Mann, A. Zimmermann, "An evaluation of Swiss agriculture's contribution to food security with decision support system for food security strategy," in Br. Food J., vol 120, pp. 2116-2128, 2018.

[9] H. Zareiforoush, S. Minaei, M.R. Alizadeh, and A Banakar, "A hybrid intelligent approach based on computer vision and fuzzy logic for quality measurement of milled rice," in Meas., vol 66, pp. 26-34, 2015.

[10] E. Giusti, and S. Marsili-Libelli, “A Fuzzy Decision Support System for irrigation and water conservation in agriculture," in Environ. Model. \& Softw., vol 63, 2015, pp. 73-86.

[11] A. Montazar, O.N. Gheidari, R.L. Snyder. "A fuzzy analytical hierarchy methodology for the performance assessment of irrigation projects," in Agric. W. Manag., vol 121, pp. 113-123, 2013.

[12] S. Petropoulos, et al., "Fuzzy logic tool for wine quality classification," in Comput. and Electron. in Agric., vol 142, pp. 552-562, 2017.

[13] Subiyanto, Hermanto, U.M. Arief, A.Y. Nafi, “An accurate assessment tool based on intelligent technique for suitability of soybean cropland: case study in Kebumen Regency, Indonesia," in Heliyon, vol 4, article $\mathrm{e} 00684,2018$

[14] Japan International Cooperation Agency, "Rice Quality", in Rice Postharvest Technology Training Program, Project Report, 2013.

[15] Japan International Cooperation Agency, "Analysis of paddy grain and rice quality in Madagascar", Tech. Guide, 2012.

[16] International Rice Research Institute (IRRI), http://www.knowledgebank.irri.org/training/fact-sheets/postharvestmanagement/rice-quality-fact-sheet-category 